\title{
CD95 Ligand (FasL)-induced Apoptosis Is Necessary for Corneal Allograft Survival
}

\author{
P. Michael Stuart, ${ }^{\star}$ Thomas S. Griffith, ${ }^{\star}$ Norio Usui, ${ }^{\star}$ Jay Pepose, ${ }^{\star \ddagger}$ Xinhong Yu, ${ }^{\star}$ and Thomas A. Ferguson ${ }^{\star \ddagger}$ \\ $*$ Department of Ophthalmology and Visual Sciences and ${ }^{\ddagger}$ Department of Pathology, Washington University School of Medicine, \\ St. Louis, Missouri 63110
}

\begin{abstract}
Although anatomical barriers and soluble mediators have been implicated in immune privilege, it appears that the apoptotic cell death of $\mathrm{Fas}^{+}$cells by tissue-associated CD95 ligand (Fas ligand, FasL) is an important component. One clinical example of the function of an immune privileged site is the success of human corneal transplants, where a very high percentage of transplants accept without tissue matching or immunosuppressive therapy. Since the mouse cornea expresses abundant Fas ligand and immune privilege has been implicated in the success of these transplants, we examined the role of FasL in corneal transplantation. Our results show that human corneas express functional FasL capable of killing $\mathrm{Fas}^{+}$lymphoid cells in an in vitro culture system. Using a mouse model for corneal allograft transplantation, $\mathrm{FasL}^{+}$orthografts were accepted at a rate of $45 \%$, whereas $\mathrm{FasL}^{-}$grafts, or normal grafts transplanted to $\mathrm{Fas}^{-}$mice, were rejected $100 \%$ of the time. Histological analysis found that $\mathrm{FasL}^{+}$grafts contained apoptotic mononuclear cells indicating the induction of apoptosis by the graft, while rejecting FasL $^{-}$corneas contained numerous inflammatory cells without associated apoptosis. Taken together our results demonstrate that FasL expression on the cornea is a major factor in corneal allograft survival and, thus, we provide an explanation for one of the most successful tissue transplants performed in humans. (J. Clin. Invest. 1997. 99:396-402.) Key words: Fas ligand • immune privilege $\bullet$ transplantation $\cdot$ cell death $\cdot$ keratoplasty
\end{abstract}

\section{Introduction}

In the United States more than 43,000 corneal transplants are performed each year, making it the most common form of solid tissue transplantation, and second only to bone transplants in overall numbers performed (1). These transplants are performed to improve vision and increase the quality of life in patients with damaged or diseased corneas making this transplantation of significant clinical and biological relevance. Cor-

Address correspondence to Thomas A. Ferguson, Ph.D., Department of Ophthalmology and Visual Sciences, 660 S. Euclid, Box 8096, Washington University School of Medicine, St. Louis, MO 63110. Phone: 314-362-3745; FAX: 314-362-3638.

Received for publication 7 October 1996 and accepted in revised form 21 November 1996.

J. Clin. Invest.

(C) The American Society for Clinical Investigation, Inc. 0021-9738/97/02/0396/07 \$2.00

Volume 99, Number 3, February 1997, 396-402 neal transplantation is also one of the most successful types of transplantation with failure rates at only 10-15\% after 1 yr (2) and $\sim 30 \%$ after 5 yr (3). Similar results have been noted in murine models of allogeneic corneal transplantation where $35-60 \%$ maintain clear grafts 9 wk after surgery. The high acceptance rate of these allografts has been ascribed to the immune privileged nature of the anterior chamber of the eye (4-6), as well as other factors such as the avascular and alymphatic nature of the graft bed, the relative absence of antigen presenting cells, the elaboration of immunosuppressive factors by the cornea (7), the low expression of MHC molecules (8), and the induction of immune deviation to corneal antigens $(4,6)$.

Recently there has been considerable interest in the role of Fas/Fas ligand (FasL) ${ }^{1}$ interactions in immune privilege $(9,10)$ and immune tolerance (11). The Fas system is recognized as a mechanism of clonal deletion after in vivo exposure to peptide or superantigen $(12,13)$, as well as a means for controlling $\mathrm{T}$ cell expansion during immune responses (14). In mice and humans, mutations in the Fas or FasL proteins lead to lymphoproliferative disorders due to the inability to control clonal expansion $(15,16)$. Recently we reported that FasL expression in the eye helped control the proliferation of lymphoid cells in this organ (9) and that Fas-mediated apoptosis of T cells was necessary for one form of immune deviation (11). These results suggest that there are parallels between immune privilege and tolerance to antigens found in important anatomical areas where antigens may not have been perceived in the thymus for clonal deletion. The ability of the eye to kill invading inflammatory cells helps maintain immune privilege and minimize bystander tissue damage, while tolerance regulates dangerous inflammatory reactions to prevent autoimmunity (17).

There has also been interest in the Fas/FasL system in transplantation biology. Bellgrau et al. (10) demonstrated that FasL expressed by Sertoli cells of the testis protected these cells from rejection when transplanted heterotopically to the kidney capsule. Similarly, Lau et al. (18) were able to prevent rejection of allogeneic pancreatic islet cells by cotransplantation with $\mathrm{FasL}^{+}$myoblasts (also transplanted to the kidney capsule). These observations were presumably the result of the induction of apoptotic cell death in $\mathrm{Fas}^{+}$cells infiltrating the grafts by the $\mathrm{FasL}^{+}$graft tissue. While no data were available in these studies on the mechanism of protection or the immune response to the transplants $(10,18)$, it offered the possibility that FasL may function in certain clinical situations to prevent graft rejection by killing sensitized effector cells arriving in the graft from the lymphoid system, similar to what happened during inflammation in the eye (9). The implication of these studies is that manipulation of the Fas-FasL system might provide significant protection for allografts.

1. Abbreviations used in this paper: FasL, Fas ligand; P815-huFas, P815 transfected with human Fas. 
There is abundant FasL expression throughout the eye, including the retina, iris/ciliary body, and the cornea (9). It is strategically placed at or near areas that comprise the bloodocular barrier, as well as in locations where there is an opportunity for potential interaction between ocular tissue and inflammatory cells. In the cornea, fully functional FasL is expressed on the endothelium and epithelium, suggesting its importance in controlling inflammatory cells that would enter from the conjunctiva or anterior chamber. The distribution of FasL on the cornea suggested that it might also be a factor in the success of corneal grafts. Here we demonstrate that human corneas, like those in the mouse, express FasL on the endothelium and epithelium capable of killing $\mathrm{Fas}^{+}$cells. In a murine model of corneal allograft transplantation, $\mathrm{FasL}^{+}$corneas were successfully engrafted at a rate of $45 \%$, while no $\mathrm{FasL}^{-}$ corneas were accepted. Furthermore, $\mathrm{FasL}^{+}$grafts transplanted to Fas-deficient mice were also never accepted. Our results demonstrate that constitutive FasL expression on the cornea plays a significant role in corneal allograft acceptance, and we provide an additional explanation for the high acceptance rate of human corneal transplants.

\section{Methods}

Mice. Female C57BL/6 (B6, H-2 $\left.{ }^{\mathrm{b}}\right)$ and BALB/c $\left(\mathrm{H}-2^{\mathrm{d}}\right)$ mice were purchased from The National Center Institute (Frederick, MD). Female and male B6-gld and B6-lpr mice were purchased from The Jackson Laboratories (Bar Harbor, ME). All mice were used at 7-10 wk of age.

Immunohistochemical staining of human corneal tissue. Human corneas, ranging from $15 \mathrm{~d}$ to $75 \mathrm{yr}$ old, were obtained from the MidAmerica Transplantation Association (St. Louis, MO). Corneas were surgically removed and quick frozen in OCT compound (Miles Inc., Elkhart, IN) with 2-methylbutane in dry ice within 1-3 d of removal. $10-\mu \mathrm{m}$ sections were cut and mounted on microscope slides, and then air dried for $30 \mathrm{~min}$. After fixation in $4 \%$ paraformaldehyde for $1 \mathrm{~h}$, sections were rinsed in PBS and endogenous peroxidase quenched with $1.0 \% \mathrm{H}_{2} \mathrm{O}_{2}$ for $5 \mathrm{~min}$ at room temperature. Sections were rinsed twice in PBS and blocked with 5\% normal goat serum and $0.3 \%$ Triton-X in PBS for $30 \mathrm{~min}$ at room temperature. Polyclonal anti-FasL antibody (Santa Cruz Biotechnology, Santa Cruz, CA) was added to the sections at $0.1 \mu \mathrm{g} / \mathrm{ml}$ in $1 \%$ normal goat serum and $0.3 \%$ Triton-X in PBS for $1 \mathrm{~h}$ at room temperature. Sections were washed three times for $5 \mathrm{~min}$ in PBS followed by the addition of peroxidase-conjugated goat anti-rabbit Ig $(1 \mu \mathrm{g} / \mathrm{ml}$, Jackson ImmunoResearch, West Grove, PA) for $1 \mathrm{~h}$ at room temperature. After incubation, sections were washed three times for $5 \mathrm{~min}$ in PBS and antibody location was determined with the addition of DAB substrate (ImmunoPure metal enhanced DAB substrate kit; Pierce, Rockford, IL) for $5 \mathrm{~min}$. Color development was stopped by washing in tap water.

$R T-P C R$ for human Fas ligand. Human corneas (Mid-America Transplantation Association) were minced into small pieces with scissors and then digested with $150 \mathrm{U} / \mathrm{ml}$ collagenase type I (Sigma Chemical Co., St. Louis, MO) overnight at $4^{\circ} \mathrm{C}$. The digest was pelleted and total RNA was isolated with TRIzol reagent (Life Technologies, Gaithersburg, MD) as per manufacturer's instructions. Total RNA was also isolated from human peripheral blood lymphocytes $\left(10^{7}\right)$ and $\mathrm{HeLa}\left(10^{7}\right)$ cells by first pelleting the cells, followed by RNA extraction with TRIzol reagent. Human PBLs were activated for $6 \mathrm{~h}$ with $0.1 \mu \mathrm{g} / \mathrm{ml}$ PMA and $0.5 \mu \mathrm{g} / \mathrm{ml}$ ionomycin before RNA extraction. RNA samples $(1 \mu \mathrm{g}$ each) were tested for DNA contamination by 40 cycles of PCR with human $\beta$-actin primers. After it was shown that there was no DNA contamination, cDNA synthesis was performed using an RNA PCR kit (Perkin Elmer, Norwalk, CT) with the supplied oligo $d(T)_{16}$ primer. Reverse transcription was performed us- ing a thermal program of $25^{\circ} \mathrm{C}$ for $10 \mathrm{~min}, 42^{\circ} \mathrm{C}$ for $30 \mathrm{~min}$, and $95^{\circ} \mathrm{C}$ for $5 \mathrm{~min}$. PCR reactions were then done using primers specific for human FasL and $\beta$-actin: FasL (forward: 5'-GCTCTAGAGCCACCATGCAGCAG-3'; reverse: 5'-GCAGATCTTAGTGGAGGCAGTGG-3') and $\beta$-actin (forward: 5'GAAACTACCTTCAACTCCATC-3'; reverse: 5'-CGAGGCCAGGATGGAGCCGCC-3') giving a 220-bp and 219-bp product, respectively. Conditions for PCR were optimized to give only the desired product. Human FasL PCR cycle conditions were: $95^{\circ} \mathrm{C}$ for $1 \mathrm{~min}, 55^{\circ} \mathrm{C}$ for $2 \mathrm{~min}$, and $72^{\circ} \mathrm{C}$ for $2 \mathrm{~min}$ for 40 cycles. Human $\beta$-actin cycle conditions were $95^{\circ} \mathrm{C}$ for $0.75 \mathrm{~min}$, $55^{\circ} \mathrm{C}$ for $1 \mathrm{~min}$, and $72^{\circ} \mathrm{C}$ for $0.75 \mathrm{~min}$ for 25 cycles. Samples were resolved on $4 \%$ agarose gel and visualized with ethidium bromide.

In vitro killing of P815 cells transfected with human FasL by human corneas. The use of whole corneas in vitro to induce Fas-mediated killing has been described (9) and was adapted here to human tissue. Human corneas (Mid-America Transplantation Association) were placed in 24-well plates with either the endothelium or epithelium facing up. The mastocytoma P815 transfected with human Fas (P815-huFas; kindly provided by Dr. Douglas Green, La Jolla Institute for Allergy and Immunology, La Jolla, CA) or parental P815 cells were labeled for $2 \mathrm{~h}$ with $5 \mu \mathrm{Ci} / \mathrm{ml}\left[{ }^{3} \mathrm{H}\right]$ thymidine at $37^{\circ} \mathrm{C}$ in DMEM $/ 10 \%$ FCS. Cells were washed twice with HBSS and resuspended in DMEM $/ 10 \%$ FCS. The target cells $\left(2 \times 10^{5}\right)$ were placed on the cornea and cultured for $20 \mathrm{~h}$ at $37^{\circ} \mathrm{C}$. Unfragmented labeled DNA was collected by filtration through glass fiber filters (Packard Instruments, Meriden, CT) using a Filtermate 96 cell harvester (Packard Instruments) and counted on a Microplate scintillation counter (Packard Instruments). Data are expressed as percent DNA fragmentation: $100 \times(\mathrm{cpm}$ from cells not cultured with cornea $-\mathrm{cpm}$ in experimental group per cpm from cells not cultured with cornea) \pm SE. Specificity of killing was determined by inclusion of the chimeric protein Fas-Fc or TNFR-Fc (10 $\mu \mathrm{g} / \mathrm{ml})(19)$.

Orthotopic corneal grafting. Corneal transplantation was performed as described previously $(4,5)$. Briefly, both donor and recipient mice were anesthetized by intraperitoneal injection of Nembutal sodium solution (Phenobarbital, $50 \mathrm{mg} / \mathrm{kg}$ ). Donor corneal grafts were prepared by removing a central $2.0 \mathrm{~mm}$ corneal button from B6, B6-gld, or BALB/c mice using an inner edged trephine (Storz, St. Louis, MO) and Vannas scissors (Storz) and placed in chilled Optisol solution (Chiron, Irvine, CA) until the recipient corneal graft bed was prepared. The recipient corneal graft bed was prepared by removing a central $2.0 \mathrm{~mm}$ corneal button from BALB/c or B6-lpr recipient mice using an outer edged trephine (Storz) and Vannas scissors. The donor corneal button was then immediately applied to the graft bed and secured in place with 12 interrupted sutures (11-0 monofilament nylon, $70 \mu \mathrm{m}$ diameter needle, Sharp-point; Vanguard, Houston, TX). Ocumycin ointment (Pharmafair, Hauppauge, NY) was placed on the corneal surface for $8 \mathrm{~d}$ after the surgery to prevent bacterial infection. All grafted eyes were examined with a vertically mounted slit-lamp biomicroscope (Marco, Jacksonville, FL) and sutures were removed $4 \mathrm{~d}$ after surgery. At this time, recipient mice with signs of surgical complications such as hyphema, cataract, shallow or flat anterior chamber, or opacity score of $4+$, were excluded from use. Grafts remaining in the study (19 for each group) were scored by two masked observers for opacity and neovascularization as described previously $(4,5)$. Grafts were scored as rejected on the day that the opacity scores reached $2+$ and data are plotted as means survival time. In this study, all grafts that reached a mean opacity score of $2+$ maintained that score or higher until the end of the study $(50 \mathrm{~d})$.

In situ TUNEL staining. At various days after corneal transplantation, eyes were removed, fixed in formalin, and processed for paraffin sectioning. $10-\mu \mathrm{m}$ sections were mounted onto microscope slides and incubated overnight at $55^{\circ} \mathrm{C}$. Sections were then deparaffinized by washing twice for $5 \mathrm{~min}$ in xylene, twice for $5 \mathrm{~min}$ in $100 \%$ ethanol, $3 \mathrm{~min}$ in $95 \%$ ethanol, $3 \mathrm{~min}$ in $70 \%$ ethanol, and $5 \mathrm{~min}$ in PBS. Protein present in the sections was digested with $20 \mu \mathrm{g} / \mathrm{ml}$ Proteinase K for $20 \mathrm{~min}$ at room temperature. After four washes in distilled water, endogenous peroxidase was quenched with $2.0 \% \mathrm{H}_{2} \mathrm{O}_{2}$ for $5 \mathrm{~min}$ at 

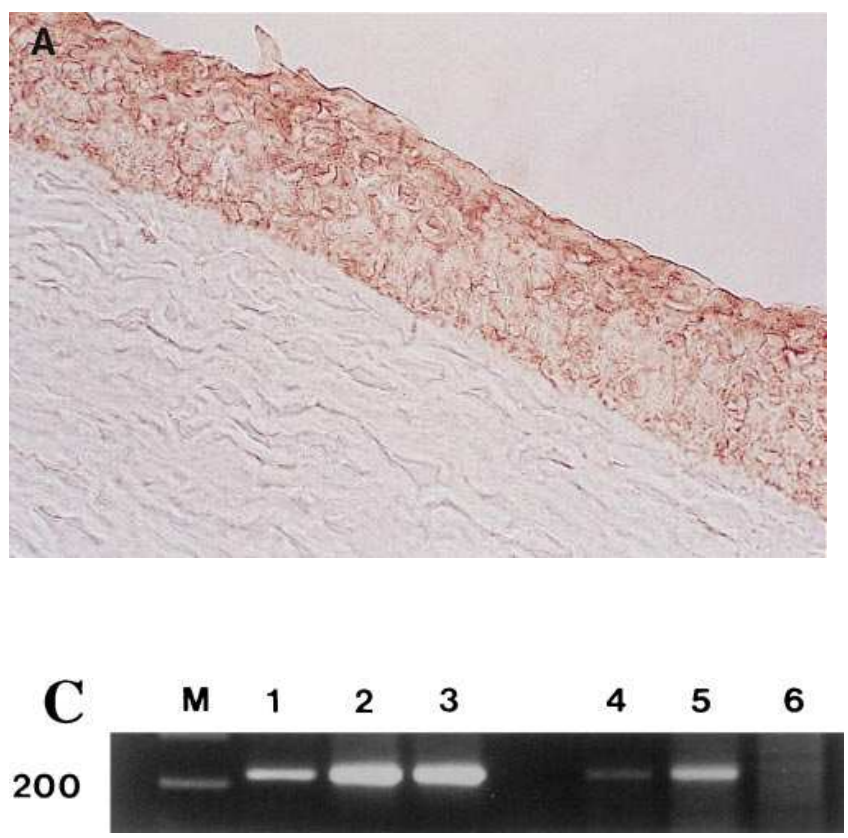

room temperature and sections were washed twice in PBS. Labeling of 3'-OH fragmented DNA ends was performed with an in situ apoptosis detection kit (ApopTag; Oncor, Gaithersburg, MD) following package instructions. Detection of labeled ends was done with the kit supplied anti-digoxigenin-peroxidase antibody and development of DAB substrate (DAB substrate kit; Vector, Burlingame, CA).

\section{Results}

Human corneas constitutively express functional FasL. Recently, we showed that FasL was constitutively and functionally expressed on mouse corneal endothelium and epithelium (9). This suggested that if FasL were expressed in a similar pattern on hu-

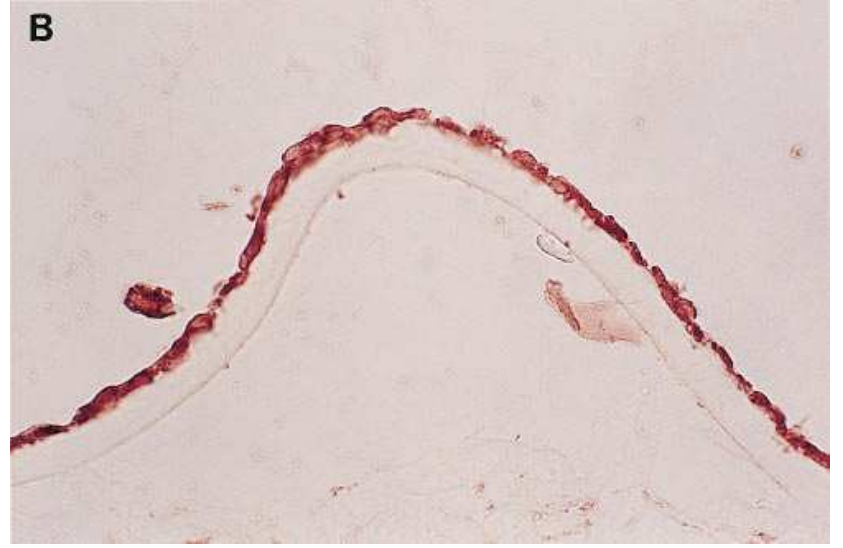

Figure 1. Human corneas express Fas ligand. Localization of FasL protein to the human corneal epithelium $(A)$ and endothelium $(B)$ by immunohistochemistry with anti-FasL antibody. $\times 400$. (C) RT-PCR analysis of human corneal tissue, PMA + ionomycin activated human PBLs, and HeLa cells for human $\beta$-actin mRNA (lanes 1-3, respectively) and FasL mRNA (lanes 4-6, respectively). $M$, molecular weight marker lane.

man corneas, it might play a role in the success of human allografts. We examined the human cornea for FasL expression by immunohistochemistry and found significant staining on the epithelium and endothelium (Fig. 1, $A$ and $B$ ). To confirm expression of FasL on this tissue, RT-PCR analysis was performed and the results in Fig. $1 C$ show FasL mRNA was present in human corneas.

Although FasL expression in the human cornea was similar to that seen in the mouse, we wanted to determine if the human corneal FasL was functional. Human corneas were cultured such that the endothelium or epithelium was placed in contact with the mouse mastocytoma P815 containing the human Fas gene (P815-huFas). Data in Fig. 2 show that the pa-

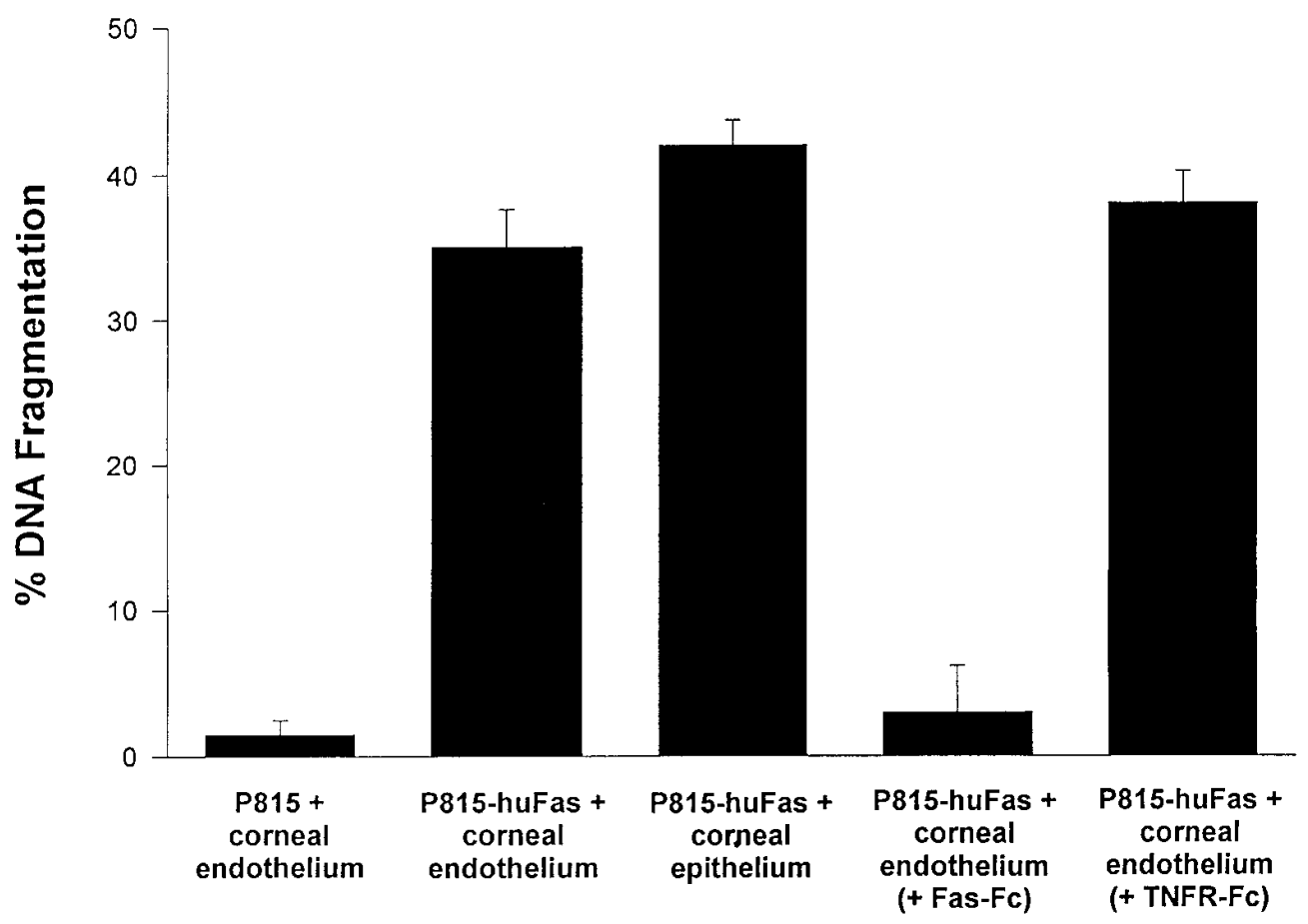

Figure 2. Human corneas express functional Fas ligand. $\left[{ }^{3} \mathrm{H}\right]$ Thymidine labeled $\mathrm{P} 815$ or P815-huFas cells $\left(2 \times 10^{5}\right)$ were cultured in contact with either the corneal epithelium or endothelium in vitro for $20 \mathrm{~h}$ at $37^{\circ} \mathrm{C}$. In some cultures the chimeric proteins Fas-Fc $(10 \mu \mathrm{g} /$ $\mathrm{ml})$ or TNFR-Fc $(10 \mu \mathrm{g} / \mathrm{ml})(19)$ were included for the entire incubation period. The amount of apoptotic cell death was determined by calculating percent DNA fragmentation. Each value represents the mean of three replicate cultures $\pm \mathrm{SE}$, and each culture condition was performed at least three times. 

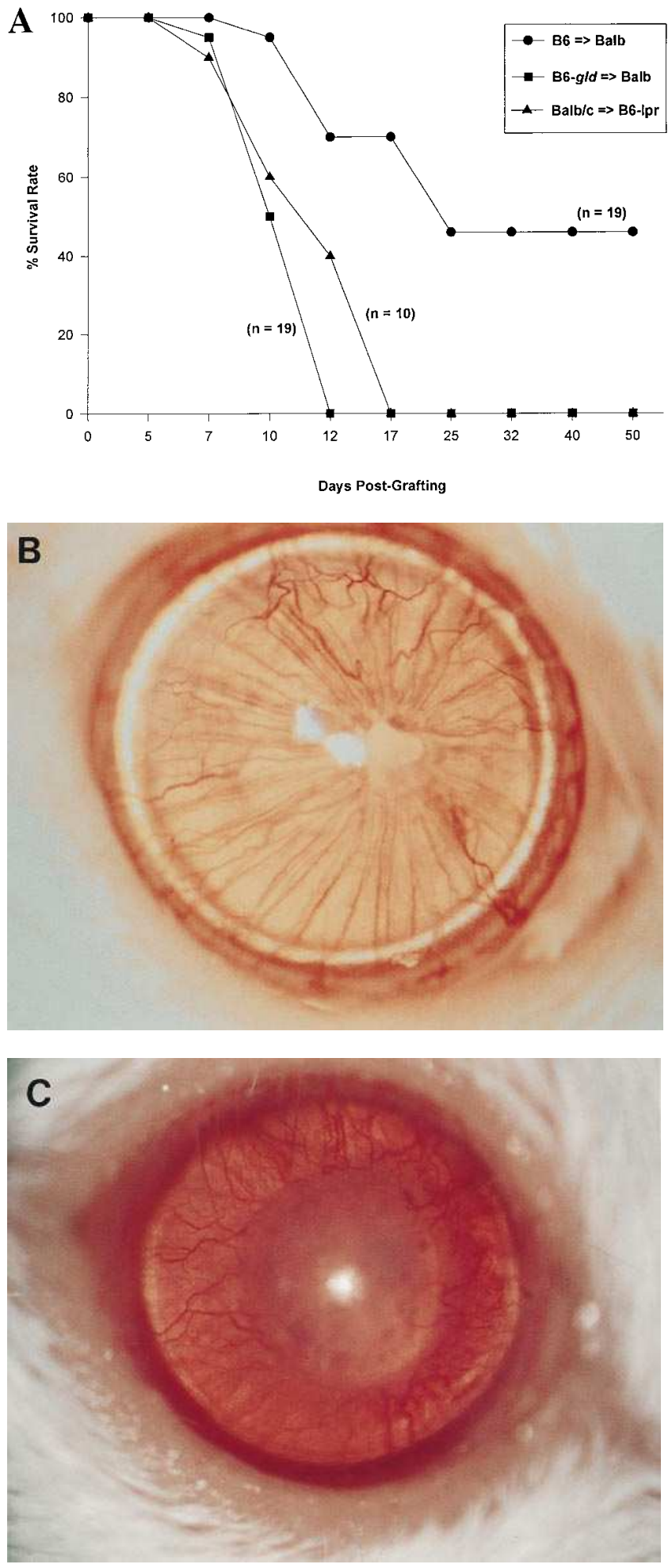

Figure 3. Mean survival time of mouse corneal allografts. $(A)$ Orthotopic corneal grafts were performed by placing $\mathrm{B} 6\left(\mathrm{FasL}^{+}, n=19\right)$ or B6-gld (FasL $\left.{ }^{-}, n=19\right)$ corneas onto BALB/c mice, as well as BALB/c $\left(\mathrm{FasL}^{+}, n=10\right)$ corneas onto B6-lpr mice $\left(\mathrm{Fas}^{-}\right)$. Grafts were observed daily for signs of rejection over $50 \mathrm{~d}$ and were scored by two masked observers for opacity and neovascularization on a scale of $1-4+$ as described $(4,5)$. Data are plotted as mean survival time where grafts were scored as rejected on the day that the opacity scores reached $2+$. In this study, all grafts that reached a mean opacity score of $2+$ maintained that score or higher until the end of the study (50 d). (B) Photograph of accepted (B6 $\rightarrow$ BALB/c) graft and $(C)$ rejected (B6-gld $\rightarrow \mathrm{BALB} / \mathrm{c}$ ) graft $25 \mathrm{~d}$ after transplantation. rental P815 was not killed by human corneal endothelium, but the P815-huFas was induced to undergo apoptosis when in contact with either the corneal endothelium or epithelium. The addition of the chimeric molecule Fas-Fc, composed of extracellular domain of human Fas fused to human immunoglobulin heavy chain (19), blocked cell death, confirming that the observed apoptotic cell death was due to Fas/FasL interactions.

Fas ligand expression and corneal graft acceptance. While FasL is important in the maintenance of immune privilege by killing invading inflammatory cells and protecting heterotopic grafts of Sertoli cells (10) or pancreatic islets (18) to the kidney capsule, FasL has not yet been shown to play a role in any clinically performed orthotopic transplantation. Since allogeneic corneal transplants enjoy a high acceptance rate without the use of antirejection therapy, we tested the possibility that FasL expressed by the cornea might play a role in a murine model of orthotopic corneal allografting. In this model, it is known that mouse corneal transplantation results in a success rate of 40 $60 \%$, where failures have been attributed to a variety of mechanisms (4-6). We compared the fate of corneal allografts from B6 $\left(\mathrm{FasL}^{+}\right)$mice with those from B6-gld $\left(\mathrm{FasL}^{-}\right)$engrafted onto $\mathrm{BALB} / \mathrm{c}$ mice. B6 corneas engrafted onto BALB/c mice observed a $45 \%$ acceptance rate. In contrast, all B6-gld corneas were rejected by BALB/c recipients (Fig. $3 A$ ). The kinetics of rejection indicated B6-gld corneas were rejected by $11 \mathrm{~d}$ (mean survival time of $10.6 \pm 0.1 \mathrm{~d}$ ), while B6 corneas did not reject until $15 \mathrm{~d}$ after engraftment (mean survival time of 14.5 \pm 2. $0 \mathrm{~d}$ ) with three rejections not occurring until day 25 (Fig. $3 A$ ). Thus, rejection of B6-gld corneas was consistently much more rapid than that of B6 tissue. Furthermore, the severity of the rejection, as measured by mean opacity scores, was much greater for B6-gld corneal grafts than B6 grafts (3.5 \pm 0.2 vs. $2.2 \pm 0.5$, respectively, $P<0.05)$. To further test our hypothesis that the Fas/FasL interaction was a crucial factor, we grafted BALB/c corneas onto B6-lpr mice (Fig. $3 A$ ). These data show that in Fas-defective mice, normal corneas are rejected with the same kinetics as $\mathrm{FasL}^{-}$corneas are on normal mice. Thus, FasL expression on corneal tissue and functional Fas on infiltrating lymphoid cells are critical for corneal graft survival. Fig. $3 B$ and $C$ are photographs of nonrejecting B6 corneas $(B)$ and rejecting $\mathrm{B} 6-$ gld $(C)$ on $\mathrm{BALB} / \mathrm{c}$ mice $25 \mathrm{~d}$ after transplantation.

Orthotopic tail skin grafts between these same combinations were also performed as described (20). Unlike the pattern seen for corneal grafts, all allogeneic skin graft combinations were rejected by $12 \mathrm{~d}$ with no significant differences in mean survival times. Syngeneic BALB/c skin grafts showed no signs of rejection on day 35 when the experiment was terminated (data not shown). These data are consistent with our observations that the skin does not express constitutive FasL (9).

FasL on the transplanted cornea induces apoptosis in infiltrating cells. We have demonstrated previously that inflammatory cells entering the eye in response to infection are induced to undergo apoptosis by FasL expressed on ocular tissue (9, 11). When the eye was FasL defective (e.g., B6-gld) no evidence of apoptosis was observed and inflammation was uncontrolled, resulting in damage to the eye. In this experimental model, inflammatory cells began to enter the corneal allografts within 3-4 d of engraftment resulting in a slight increase in opacity of most grafts by days 7-9 (4-5). A significant percentage of the corneas from B6 mice began to clear by day 14 and 

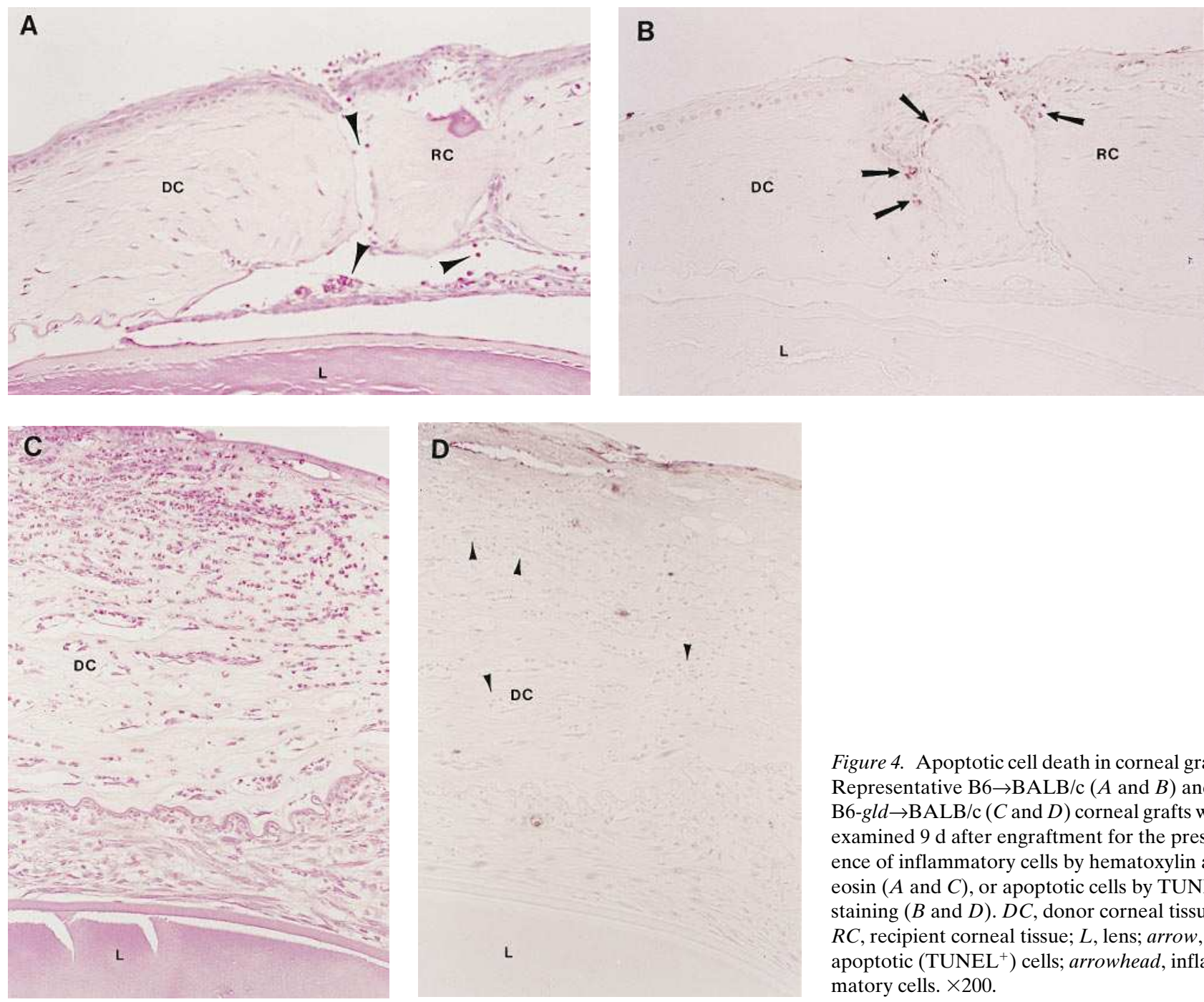

Figure 4. Apoptotic cell death in corneal grafts. Representative $\mathrm{B} 6 \rightarrow \mathrm{BALB} / \mathrm{c}(A$ and $B)$ and B6-gld $\rightarrow \mathrm{BALB} / \mathrm{c}(C$ and $D)$ corneal grafts were examined $9 \mathrm{~d}$ after engraftment for the presence of inflammatory cells by hematoxylin and eosin $(A$ and $C)$, or apoptotic cells by TUNEL staining $(B$ and $D) . D C$, donor corneal tissue; $R C$, recipient corneal tissue; $L$, lens; arrow, apoptotic $\left(\mathrm{TUNEL}^{+}\right)$cells; arrowhead, inflammatory cells. $\times 200$.

maintained clarity throughout the observation period. In contrast, none of the B6-gld corneas demonstrated a reduction in opacity. To determine if the induction of apoptosis might be involved in the clearing and protection of the grafts, we examined these tissues for apoptotic cells during this critical period (days 5-14). Fig. $4 A$ shows that at day 9 after grafting a few mononuclear cells are infiltrating the B6 corneal tissue accounting for the observed opacity $(4,5)$. Fig. $4 B$ is a serial section from the same graft on which a TUNEL stain was performed to detect apoptotic cells. This shows that the few mononuclear cells that were present in the graft were apoptotic. In contrast, B6-gld corneas have numerous inflammatory cells infiltrating the cornea on day 9 (Fig. $4 C$ ), but no apoptotic cells were detected by TUNEL staining (Fig. $4 \mathrm{D}$ ). Thus, mononuclear cells that infiltrated $\mathrm{FasL}^{+}$allogeneic corneal tissue were induced to undergo apoptosis thereby promoting graft acceptance. When corneal tissue was incapable of inducing apoptosis (i.e., FasL $^{-}$) graft rejection ensued.

\section{Discussion}

In this paper we demonstrate that the high rate of orthotopic corneal graft acceptance depends on constitutive FasL expres- sion on the transplanted tissue. Human corneas expressed FasL on the endothelium and epithelium that was capable of killing $\mathrm{Fas}^{+}$lymphoid cells. In a murine model of corneal allograft transplantation, FasL $^{-}$corneas were never accepted and $\mathrm{Fas}^{-}$mice did not accept normal $\mathrm{FasL}^{+}$grafts. This compares with a $45 \%$ acceptance rate with $\mathrm{FasL}^{+}$corneas on normal mice. We also observed that $\mathrm{FasL}^{+}$grafts can induce cell death in invading lymphoid cells, while $\mathrm{FasL}^{-}$tissue was incapable of doing so. Thus, our data demonstrate that FasL expression is a critical factor determining the success of orthotopic corneal allografts by inducing cell death in inflammatory cells.

Most of what is known about immune privileged sites has come from studies in the eye and it is established that a number of components contribute to this unique microenvironment. Immunosuppressive factors $(21,22)$, limited MHC expression, lack of lymphatic drainage $(7,11)$, specialized antigen presenting cells (22), and the tendency to induce immune deviation (11, 23-25) after anterior chamber injection of antigens have all been associated with immune privilege. We now know that constitutive expression of FasL also contributes significantly to immune privilege. FasL kills lymphoid cells invading the site, but when FasL is defective (e.g., in mice with the gld mutation) 
inflammatory responses can overwhelm the organ causing significant damage (9).

We showed recently that apoptotic cell death induced by FasL in the eye is also a critical factor in the induction of immune deviation to viral and cellular antigens presented via the anterior chamber of the eye (11). The induction of immune deviation to the corneal alloantigens has also been associated with corneal graft survival $(4,6)$ and the result of the presentation of corneal antigens via the anterior chamber route. The response is termed anterior chamber associated immune deviation (ACAID) and is characterized by an inhibited DTH, with the simultaneous activation of antibody production (11, 23-25). It has been shown that animals with impaired DTH to corneal alloantigens generally have healthy allografts, while those animals that have a vigorous DTH response to the alloantigens have rejected their grafts (4-6). Although this is likely a failure to prime in most cases, it does suggest a correlation between DTH responses and graft success. Here we show that apoptotic mononuclear cells can be observed in allogeneic corneal grafts. Since we have shown that apoptotic death of lymphocytes in the eye leads to immune deviation (11), we can speculate that FasL-induced cell death in the grafts may play a role in the establishment of immune deviation to graft alloantigens.

Corneal transplants do not require genetic manipulation to get FasL expression (9), and more importantly they are placed onto the site which is immune privileged by nature. Thus, while FasL expression appears to be a major component in graft acceptance, the site of transplantation likely plays an important role. This is illustrated by the observation that corneas grafted heterotopically to the skin are rapidly rejected (7), suggesting that constitutive expression of FasL on corneal epithelium and endothelium must either be influenced by the local ocular microenvironment or are ineffective at this site. The profile of cytokines and neuropeptides in the skin is very different from the eye (21) as is the outcome of antigen presentation. The skin is known to be an effective route for the induction of potent systemic immunity (26) while the eye is a potent route of tolerance induction $(11,23-25)$. Perhaps the environment of the skin does not allow for constitutive FasL expression, or perhaps the absence of immunosuppressive cytokines and neuropeptides (21) found in the eye is a factor. It is even possible that the skin can downmodulate FasL expression. It is also important to note that the skin is vascularized, a factor known to affect corneal graft survival (27). Whether vascularization in any area influences FasL expression or whether the presence of vessels allows lymphoid cells to simply overwhelm the Fas/FasL system is a matter of current investigation. Whatever the explanation for the disparity in graft survival between skin and the eye, we would offer the caution that merely expressing FasL in a tissue may not be sufficient in all transplantation settings to ensure survival and that other factors should be considered.

Solid tissue transplantation is one of the most frequently performed surgeries in the world. For many, this type of surgery represents the last hope for recovery from a life-threatening or debilitating crisis. Most forms of transplantation require extensive tissue matching and additional immunosuppressive therapy to increase the chance for acceptance of the grafted organ. Unfortunately, these precautions do not guarantee success and the transplant can still be rejected. Corneal transplantation, on the other hand, has enjoyed many years of high suc- cess rates without any of the usual methods used to enhance graft acceptance (1-3). Recent studies with FasL have shown the potential of manipulating this molecule to improve the success of tissue grafting. Results showing the successful heterotopic transplantation of $\mathrm{FasL}^{+}$Sertoli cells (10) and pancreatic islets (18) suggest that this may be a viable approach to prevent immune attack. We would even suggest that the level expression of FasL on corneal grafts may be predictive of their success in the human transplant situation. It may even be possible to increase FasL expression on corneal tissue before grafting to ensure an even higher rate of survival. Whatever the ultimate use of the Fas-FasL system in transplantation biology, our data provide an explanation for the success of one of the most frequently performed tissue transplants in humans.

\section{Acknowledgments}

The authors would like to acknowledge the fine technical assistance of Dr. Chun-Ki Joo, Mr. John Herndon, Dr. Keith Laycock, and Ms. Veronica Franklin.

This work was supported by National Institutes of Health grants EY06765 (T.A. Ferguson), EY09751 (J.S. Pepose), and EY02687 (Department of Ophthalmology Core Grant) from the National Eye Institute, and a Department of Ophthalmology and Visual Sciences grant from Research to Prevent Blindness, Inc., New York, NY. P.M. Stuart is the recipient of an Arthritis Foundation Investigator Award and a career development award from Research To Prevent Blindness. J.S. Pepose is the recipient of a Senior Investigator Award from Research to Prevent Blindness, Inc.

\section{References}

1. Brady, S.E., J.C. Rapuano, J.J. Arentsen, E.J. Cohen, and P.R. Laibson. 1989. Clinical indications and procedures associated with penetrating keratoplasty. Am. J. Ophthalmol. 108:118-122.

2. Vail, A., S.M. Gore, B.A. Bradley, D.L. Easty, and C.A. Rogers. 1993. Corneal transplant follow-up study. Invest. Ophthalmol. Vis. Sci. 34A:1366.

3. Council on Scientific Affairs. 1988. Report of the Organ Transplant Panel: Corneal Transplantation. JAMA (J. Am. Med. Assoc.). 259:719-722.

4. Joo, C.-K., J.S. Pepose, and P.M. Stuart. 1995. T-cell mediated responses in a murine model of orthotopic corneal transplantation. Invest. Ophthalmol. Vis. Sci. 36:1530-1540.

5. Joo, C.-K., J.S. Pepose, K.A. Laycock, and P.M. Stuart. 1994. Allogeneic graft rejection in a murine model of orthotopic corneal transplantation. In Advances in Ocular Immunology. R.B. Nussenblatt, S.M. Whitcup, R.R. Caspi, and I. Gery, editors. Elsevier Science B.V., Amsterdam, The Netherlands. 115-118.

6. Sonoda, Y., and J.W. Streilein. 1993. Impaired cell-mediated immunity in mice bearing healthy orthotopic corneal allografts. J. Immunol. 150:1727-1734.

7. Niederkorn, J.Y., D. Callahan, and J.R. Ross. 1990. Prevention of the induction of allospecific cytotoxic T lymphocyte and delayed hypersensitivity responses by ultraviolet irradiation of corneal allografts. Transplantation (Baltimore). 50:281-286.

8. Goldberg, M., T.A. Ferguson, and J.S. Pepose. 1994. Detection of cellular adhesion molecules in inflamed human corneas. Ophthalmology. 101:161.

9. Griffith, T.S., T. Brunner, S.M. Fletcher, D.R. Green, and T.A. Ferguson. 1995. Fas ligand-induced apoptosis as a mechanism of immune privilege. Science (Wash. DC). 270:1189-1192.

10. Bellgrau, D., D. Gold, H. Selawry, J. Moore, A. Franzusoff, and R.C. Duke. 1995. A role for CD95 ligand in preventing graft rejection. Nature (Lond.). 377:630-632.

11. Griffith, T.S., X. Yu, J.M. Herndon, D.R. Green, and T.A. Ferguson. 1996. CD95-induced apoptosis of lymphocytes in an immune privileged site induces immunological tolerance. Immunity. 5:7-16.

12. Singer, G.G., and A.K. Abbas. 1994. The Fas antigen is involved in peripheral but not thymic deletion of $\mathrm{T}$ lymphocytes in $\mathrm{T}$ cell receptor transgenic mice. Immunity. 1:365-371.

13. Mogil, R.J., L. Radvanyi, R. Gonzalez-Quintial, R. Miller, G. Mills, A.N. Theofilopoulos, and D.R. Green. 1995. Fas (CD95) participates in peripheral T cell deletion and associated apoptosis in vivo. Int. Immunol. 7:1451-1458.

14. Ju, S.-T., D.J. Panka, H. Cui, R. Ettinger, M. El-Khatib, D.H. Sherr, B.Z. Stanger, and A. Marshak-Rothstein. 1995. Fas(CD95)/FasL interactions required for programmed cell death after T-cell activation. Nature (Lond.). 373: 444-448. 
15. Nagata, S., and T. Suda. 1995. Fas and Fas ligand: lpr and gld mutations. Immunol. Today. 16:39-43.

16. Rieux-Laucat, F., F. LeDeist, C. Hivoz, A.G. Roberts, K.M. Debatin, A. Fischer, and J.P. de Villartay. 1995. Mutations in Fas associated with human lymphoproliferative syndrome and autoimmunity. Science (Wash. DC). 268: 1347-1349.

17. Abbas, A.K. 1996. Die and let live: eliminating dangerous lymphocytes. Cell. 84:655-657.

18. Lau, H.T., M. Yu, A. Fontana, and C.J. Stoeckert, Jr. 1996. Prevention of islet allograft rejection with engineered myoblasts expressing FasL in mice. Science (Wash. DC). 273:109-112.

19. Brunner, T., R.J. Mogil, D LaFace, N.J. Yoo, A. Mahboubi, F. Echeverri, S.J. Martin, W.R. Force, D.H. Lynch, C.F. Ware, and D.R. Green. 1995. Cell-autonomous Fas (CD95)/Fas-ligand interaction mediates activation-induced apoptosis in T-cell hybridomas. Nature (Lond.). 373:441-444.

20. Stuart, P.M., R.W. Melvold, and B. Beck-Maier. 1984. Provocation of skin graft rejection across murine class II differences by non-bone marrow derived cells. Transplantation (Baltimore). 37:393-396.

21. Ferguson, T.A., S. Fletcher, J.M. Herndon, and T.S. Griffith. 1995. Neuropeptides modulate immune deviation induced via the anterior chamber of the eye. J. Immunol. 155:1746-1756.

22. Wilbanks, G., M. Mammolenti, and J.W. Streilein. 1991. Studies on the induction of anterior chamber-associated immune deviation (ACAID). II. Eyederived cells participate in generating blood-borne signals that induce ACAID J. Immunol. 146:3018-3024.

23. Kaplan, H.J., and J.W. Streilein. 1977. Immune response to immunization via the anterior chamber of the eye. I. F1 lymphocyte-induced immune deviation. J. Immunol. 118:809-814.

24. Ferguson, T.A., J. Hayashi, and H.J. Kaplan. 1989. The immune response and the eye. III. Anterior chamber associated immune deviation can be adoptively transferred by serum. J. Immunol. 143:821-826.

25. Griffith, T.S., J.M. Herndon, J. Lima, M. Kahn, and T.A. Ferguson. 1995. The immune response and the eye. T-cell receptor $\alpha$-chain related molecules regulate the systemic immunity to antigen presented via the anterior chamber of the eye. Int. Immunol. 7:1617-1625.

26. Ferguson, T.A., P. Dube, and T.S. Griffith. 1994. Regulation of contact hypersensitivity by IL-10. J. Exp. Med. 179:1597-1603.

27. Boisjoly, H.M., R. Taourigny, R. Bazin, P.A. Laughrea, I. Dube, G. Chamberland, J. Bernier, and R. Roy. 1993. Risk factors of corneal graft failure. Ophthalmology. 100:1728-1735. 